\title{
Public Trust, Deliberative Engagement and Health Data Projects: Beyond Legal Provisions
}

\author{
NISHTHA BHARTI \\ INDIAN INSTITUTE \\ OF TECHNOLOGY \\ DELHI \\ INDIA
}

\author{
CIAN O'DONOVAN \\ UNIVERSITY \\ COLLEGE LONDON \\ UNITED KINGDOM
}

\author{
MELANIE SMALLMAN \\ UNIVERSITY \\ COLLEGE LONDON \\ UNITED KINGDOM
}

\author{
JAMES WILSON \\ UNIVERSITY \\ COLLEGE LONDON \\ UNITED KINGDOM
}

\begin{abstract}
In England, a new scheme for collating and sharing General Practice data has faced resistance from various quarters and has been deferred repeatedly. While insufficient communication and ambiguous safeguards explain the widespread dissatisfaction expressed by the public and experts, we argue how dwindling public trust can be the most damaging variable in this picture - with implications not only for this scheme, but for any future project that aims to mobilise health data for medical research and innovation. We also highlight the indispensability of deliberative public engagement on the values being prioritised in health data initiatives, the significance of securing social licence in addition to legal assurances, and the lessons in it of global pertinence.
\end{abstract}

\section{Keywords}

trust; health data; public engagement; National Health Service (NHS); GPDPR

\section{Introduction}

England's National Health Service (NHS) - one of the few publicly funded, universal healthcare systems in the world-is set to roll-out a new scheme to create a centralised database of patient data extracted from General Practice (GP) records. Given the sensitive nature of the data involved, ${ }^{1}$ the announcement of the scheme-General Practice Data for Planning and Research (GPDPR) - in May 2021 has animated fierce debates around the aspirations to use sensitive health information.

${ }^{1} \mathrm{GP}$ data in England is a unique and rich repository with few international comparators - it includes holistic clinical records, both structured and unstructured, going back decades and growing in real time.

Copyright (C) 2021 (Nishtha Bharti, Cian O'Donovan, Melanie Smallman, and James Wilson). Licensed under the Creative Commons Attribution-NonCommercial-NoDerivatives 4.0 International (CC BY-NC-ND 4.0). Available at estsjournal.org.

To cite this article: Bharti, Nishtha, Cian O'Donovan, Melanie Smallman, and James Wilson. 2021. "Public Trust, Deliberative Engagement and Health Data Projects: Beyond Legal Provisions." Engaging Science, Technology, \& Society 7.1: 125-133. https://doi.org/10.17351/ests2021.1197. 
Such debates have been explored in Science and Technology Studies (STS) literature, offering a set of approaches that spotlight public deliberation, engagement and consultation, not only for accountable democratic governance but also for better outcomes from innovation initiatives (Davies 2014; Delgado et al. 2010; Jasanoff 2003a; Selin et al. 2016). We argue in this essay that these outcomes are recursively tied to public trust, since their success relies on broad public uptake and large-scale deployment. Focusing on the GPDPR scheme, we highlight the need for securing public trust and the importance of meaningful public engagement ${ }^{2}$ against a backdrop of increasing strains on citizens' confidence in data sharing strategiesgiven recent encounters with various unpopular data collecting and sharing initiatives such as care.data (Carter et al. 2015), the Facebook-Cambridge Analytica and Leave.EU campaign scandal (Hern 2019) and the NHS Covid-19 Data Store deal with Palantir (Fitzgerald and Crider 2020). We further argue that unless discussions on the inherent values and tradeoffs within these applications are encouraged and enabled, governments worldwide are likely to continue to run into "a number of practical difficulties, such as confrontation, disruption, boycott, and public distrust" (Rowe et al. 2005, 332).

\section{GPDPR and the Erosion of Public Trust}

From the start, for many, the public announcement of the GPDPR scheme seemed rushed, with GPs and medical bodies such as the British Medical Association complaining that there was insufficient information and time. Launched in May 2021, the scheme was expected to go live at the beginning of July. The reasons for this timing are unclear, but initially, patients were given just over a month to opt out from GPDPR, with the onus on GPs to notify their patients and to process patient opt-out forms - when they were already swamped with the COVID-19 vaccination programme and pre-COVID backlog. Furthermore, UK-based campaign groups such as medConfidential raised alarm over sharing a centralised database, that included sensitive personal information on sex, ethnicity and sexual orientation, with third parties. The digital rights nonprofit entity Foxglove, in partnership with a cluster of advocacy groups, launched legal proceedings against the Department of Health and Social Care, questioning the lawfulness of this new data strategy (Murgia 2021). These apprehensions were echoed by the opposition Labour party (Walker 2021).

There was an almost unanimous agreement amongst various stakeholders that NHS Digital - the national IT partner to the health and social care system in England and spearheading GPDPR - must clarify who was to get access to this data, under what terms and who would eventually benefit from such access. NHS Digital, however, did not appear to be particularly spirited to mitigate these concerns. Instead, it stipulated a limited timeframe for patients to opt out of this scheme, with hardly any information to allow patients to make an informed choice, fuelling misgivings about the trustworthiness of this exercise.

2 For an in-depth understanding of how the categories of 'engagement' and 'consultation' have been problematised in STS literature, see: Barnett et al. (2010); Irwin (2014); Lezaun and Soneryd (2007); and Thorpe and Gregory (2010). 
In early June, the government deferred the opt-out deadline until September 2021, to "provide more time to speak with patients, doctors, health charities and others" (NHS Digital 2021a). Simultaneously, NHS Digital published the latest figures of the National Data Opt-out-a service introduced in 2018 allowing patients to withdraw their data from being used for any purpose beyond their immediate care. These statistics revealed that the opt-out rate had dramatically increased in the run up to the original GPDPR opt-out deadline of June 2021. More people registered for the National Data Opt-out in May $2021(107,429)$, when plans for GPDPR were released, than in the preceding 10 months $(72,225)$ (ibid. 2021b). Following the public furore around the scheme, this figure escalated to nearly 12 -fold $(1,275,153)$ in June 2021, taking the number of optouts to more than 3 million-almost $5 \%$ of the population (ibid. 2021c). Such a staggering increase in the number of opt-outs shows that despite the legal cover provided by data protection and the common law of confidentiality (Taylor and Wilson 2019) and assurances from NHS Digital regarding its governance processes, it did not appear to have secured the 'social licence' for GPDPR, contingent on people's perception of this enterprise being in public interest and not solely contributing to commercial profiteering (Carter et al. 2015).

Such a high level of opt-outs points towards another difficulty that further threatens the prospect of gaining social legitimacy for the use of NHS data in research and planning: as more and more people register for the opt-out, the risk of the resulting database being less representative of the population increases, significantly jeopardising the generalisability of any public health modelling or clinical application developed from it (boyd and Crawford 2012). While the granular details and trends of those opting out from GPDPR are presently unclear, ${ }^{3}$ research has demonstrated that many groups, including older adults, women and minorities are generally under-represented in medical datasets (Malanga et al. 2018; Rochon et al. 2004). Any move that potentially entrenches this shortcoming could also reinforce the reservations that prompted opt-outs originally, and thus risks perpetuating the cycle of distrust in data-based ventures and their outputs amongst the general public.

In July 2021, the scheme was delayed again, with a commitment that it would not be launched until certain tests have been met (NHS Digital 2021d). These tests include the option of opting-out of the scheme and have one's data deleted even after collection has begun and the presence of a 'Trusted Research Environment' (TRE) ${ }^{4}$ for managing access to sensitive medical data. While these revisions are commendable, it is also crucial that in the time that NHS Digital has bought by delaying GPDPR, it also addresses the erosion of public trust, not only because it impacts the uptake of this project and the potential for data to be used in

\footnotetext{
${ }^{3}$ It is presently not known, for example, the race, ethnicity, income group or sexual orientation of the individuals that have opted out from the scheme. NHS Digital provides a breakdown by age, gender and geographical location. (See: NHS Digital 2021e).

4 While in traditional models of data sharing information is sent to the users/researchers under contract, in a TRE users receive access to the data within a single secure environment. (See: NHS Digital 2021f).
} 
developing new healthcare applications and research resources, but also because it is likely to affect public confidence in NHS data use more widely (Data Use Workstream 2021).

\section{Deliberative Engagement and Public Benefit}

Public resistance to technoscientific endeavours is rarely the result of an information deficit (Bucchi and Neresini 2002) or due to lack of formalised knowledge (Wynne 1989). Nor are public concerns and scepticism lightly-held views that can be alleviated with more information or reassurance (Irwin and Wynne 1996; Martin and Tait 1992). Instead, public perceptions and reactions are determined by peoples' values and their sense of how science and technology initiatives shape services and institutions, and questions regarding who ultimately benefits from these efforts (Felt et al. 2007; Smallman 2017; Whitmarsh 2011), leading to calls for greater public participation ${ }^{5}$ in decision-making processes (Jasanoff 2003b). Alongside these calls are also appeals to reckon with the ways in which emerging technologies might reinforce existing structures of inequality and discrimination (Benjamin 2019; Eubanks 2017), neglect intersectional power relations and struggles (D'Ignazio and Klein 2020), dilute contextual complexities ( for profit maximisation (Zuboff 2019). As data accumulation, monitoring and exchange accelerate globally, these technologies also offer the potential to serve as further tools to "pathologise and stigmatise" marginalised groups (Gieseking 2017, 150). Such issues have mobilised recommendations to reimagine datadriven initiatives and associated technological pursuits for more equitable and liberatory ends, more so in a way that is sensitive to competing and multifaceted notions of identity, origins and interests (Leurs 2017; TallBear 2013).

In this context, NHS Digital must build on the UK's experience of public engagement, through programmes like ScienceWise, ${ }^{6}$ to undertake deliberative engagement in the context of GPDPR, with the aim of aligning institutional visions of public interest with the range of public views. For instance, the National Data Guardian recently explored notions of 'public benefit' (Hopkins Van Mil 2021) finding (amongst other things) that the public had certain expectations about any use of health and social care data: Transparencynot just for methods and procedures, but also about the value estimated in data use; appropriate safeguards for sensitive datasets - including protection from data manipulation for profit motives; and demonstrating that benefits accrue equitably across all sections of the population-especially for those whose may be disproportionately (under)represented in health datasets. These expectations reveal that a genuine attempt at engaging the public on how 'public benefit' might be diversely interpreted can help rebuild consensus around how NHS resources should be used and shared.

5 The composition and lineations of public participation have also been interpreted as contested practices in STS scholarship (see: Goodwin 1998; Irwin 2001; and Wynne 2007).

${ }^{6}$ Sciencewise is a public engagement programme in the UK which assists policy makers to develop socially informed policy (see: Sciencewise n.d.). 
NHS Digital should also pay attention to the issues raised through lobbying and media discourse by various stakeholders ${ }^{7}$ regarding GPDPR - from the privacy concerns of GPs and professional bodies to the wider equity issues raised by NGOs and provide citizens and civil society actors the opportunity to deliberate and determine how data sharing takes place, to have a say in how the NHS itself might be shaped by data-driven technologies, as well as to influence who should be involved in developing them. Such deliberation must also involve reflection on how public values are incorporated in the ideation and execution of data projects, how they will be scrutinised and the conditions under which 'benefit' itself can be re-evaluated (Stirling 2008). While there is also a need to communicate the safeguards already in place for data sharing, the parameters for screening prospective recipients of patient data and how the desirability of potential use-cases is weighed, ${ }^{8}$ NHS Digital must be clear that the essence of engagement practices goes beyond legal reassurances. Unless citizens are invited into a negotiation about what amounts to the 'public benefit' of medical data infrastructures, the tradeoffs they are prepared to make for its sake and then offered straightforward means to exercise their choice (such as, of opting out), trust in the legitimacy of this project-and ultimately its ability to meet its potential promise-will not be restored. And as such, the manner in which the implementation of GPDPR unfolds in England will serve as an instructive case study for other countries that aspire to open up health datasets for broader use.

\section{Conclusion}

The pandemic has shown us how indispensable data is for understanding disease epidemiology, timely identification of vulnerable groups, finding effective treatments and rolling-out vaccines. It has also demonstrated how dwindling public trust can hamper meaningful adoption of critical data-driven technologies, as evident in the failure of digital contact tracing apps to be deployed at scale in many countries. It is therefore necessary to ensure that public health decisions, even in fast moving situations, are characterised by a commitment to engagement that builds trust with the wider population from the ground up. Failure to do so will not only limit the data resource base of GPDPR to have any meaningful impact for research, but it will also jeopardise the acceptability of valuable data-based initiatives in the future. NHS Digital must now venture to understand and address the dissatisfaction of both experts and concerned publics through deliberative public engagement, aiming to build consensus on what 'public benefit' and the future of the NHS looks like. While it is important to have robust legal mechanisms for responsible management and sharing of data, what is equally indispensable is the need to build collaborative agreement on how, if at all, data should be used and for what ends.

\footnotetext{
7 Such as General Practitioners, MPs, privacy campaigners, legal firms and patient groups (see: Crouch 2021; and Marsh 2021).

${ }^{8}$ These are reflected in the records of Data Access Request Service (DARS) Release Register and the responsibilities and processes of the Independent Group Advising on the Release of Data (IGARD) - all compiled and shared on NHS Digital's web pages.
} 


\section{Acknowledgements}

This work is a collaboration between Nishtha Bharti (supported by the Newton Bhabha Fund PhD Placements Programme) and Prof James Wilson, Dr Melanie Smallman and Dr Cian O'Donovan (supported by the AHRC UK Pandemic Ethics Accelerator, grant number AH/V013947/1).

Prof James Wilson is a member of the National Data Guardian's panel. The article refers to the work of the NDG but the views expressed are solely the authors' and do not necessarily represent the views of the NDG, the NDG panel, or any other organisation.

\section{Author Biographies}

Nishtha Bharti is a doctoral candidate at the Department of Humanities and Social Sciences, Indian Institute of Technology (IIT), Delhi, where she works at the intersection of Science and Technology Studies (STS) and political theory.

Cian O'Donovan is a researcher at the Department of Science and Technology Studies, University College London.

Melanie Smallman is Associate Professor in the Department of Science and Technology Studies at University College London and a Fellow at the Alan Turing Institute.

James Wilson is Professor of Philosophy at University College London, and is author of Philosophy for Public Health and Public Policy: Beyond the Neglectful State (Oxford University Press 2021).

\section{References}

Arora, Payal. 2016. "Bottom of the Data Pyramid: Big Data and the Global South." International Journal of Communication 10: 1681-1699. https://ijoc.org/index.php/ijoc/article/view/4297.

Barnett, Julie, Kate Burningham, Gordon Walker, and Noel Cass. 2010. "Imagined Publics and Engagement Around Renewable Energy Technologies in the UK." Public Understanding of Science 21(1): 36-50. https://doi.org/10.1177/0963662510365663.

Benjamin, Ruha, ed. 2019. Captivating Technology: Race, Carceral Technoscience, and Liberatory Imagination in Everyday Life. Durham : Duke University Press.

boyd, danah and Kate Crawford. 2012. "Critical Questions for Big Data: Provocations for a Cultural, Technological, and Scholarly Phenomenon." Information, Communication \& Society 15(5): 662-679. https://doi.org/10.1080/1369118X.2012.678878.

Bucchi, Massimiano, and Federico Neresini. 2002. "Biotech Remains Unloved by the More Informed." Nature 416(261). https://doi.org/10.1038/416261a.

Carter, Pam, Graeme T. Laurie, and Mary Dixon-Woods. 2015. "The Social Licence for Research: Why Care.Data Ran Into Trouble." Journal of Medical Ethics 41(5): 404-409.

http://dx.doi.org/10.1136/medethics-2014-102374. 
Crouch, Hannah. 2021. "Calls to Pause New GP Data Collection Service Gather Speed." Digital Health, June 4, 2021. https://www.digitalhealth.net/2021/06/calls-to-pause-new-gp-data-collection-servicegather-speed/.

Data Use Workstream. 2021. "Consultation on the Data Saves Lives Strategy." UK Pandemic Ethics Accelerator, July 23, 2021. https://ukpandemicethics.org/wp-content/uploads/2021/07/Data-Saves-Livessubmission-from-the-UK-Pandemic-Ethics-Accelerator-Date-use-workstream.pdf.

Davies, Sarah R. 2014. "Knowing and Loving: Public Engagement Beyond Discourse." Science \& Technology Studies 27(3): 90-110. https://doi.org/10.23987/sts.55316.

Delgado, Ana, Kamilla Lein Kjølberg, and Fern Wickson. 2010. "Public Engagement Coming of Age: From Theory to Practice in STS Encounters with Nanotechnology." Public Understanding of Science 20(6): 826-45. https://doi.org/10.1177/0963662510363054.

D'Ignazio, Catherine, and Lauren F. Klein. 2020. Data Feminism. Cambridge, MA: MIT Press.

Eubanks, Virginia. 2017. Automating Inequality: How High-Tech Tools Profile, Police, and Punish the Poor. New York: St Martin's Press.

Felt, Ulrike, and Brian Wynne, et al. 2007. "Taking the European Knowledge Society Seriously: Report of the Expert Group on Science and Governance to the Science, Economy and Society Directorate." Brussels: Directorate-General for Research and Innovation, European Commission.

Fitzgerald, Mary, and Cori Crider. 2020. "Controversial 'Spy Tech’ Firm Palantir Lands £23m NHS Data deal." openDemocracy, December 21, 2020.

https://www.opendemocracy.net/en/ournhs/controversial-tech-firm-palantir-23m-nhs-datadeal/.

Gieseking, Jen Jack. 2017. "Size Matters to Lesbians, Too: Queer Feminist Interventions into the Scale of Big Data." The Professional Geographer 70(1): 150-156.

https://doi.org/10.1080/00330124.2017.1326084.

Goodwin, Philip. 1998. “'Hired Hands' or 'Local Voice': Understandings and Experience of Local Participation in Conservation." Transactions of the Institute of British Geographers 23(4): 481-99. http://www.jstor.org/stable/623177.

Hern, Alex. 2019. "Cambridge Analytica Did Work for Leave.EU, Emails Confirm" Guardian, July 30, 2019. https://www.theguardian.com/uk-news/2019/jul/30/cambridge-analytica-did-work-for-leaveeu-emails-confirm.

Hopkins Van Mil. 2021. "Putting Good into Practice: A Public Dialogue on Making Public Benefit Assessments When Using Health and Care Data." National Data Guardian. April 14, 2021.

https://www.gov.uk/government/publications/putting-good-into-practice-a-public-dialogueon-making-public-benefit-assessments-when-using-health-and-care-data.

Irwin, Alan. 2001. "Constructing the Scientific Citizen: Science and Democracy in the Biosciences." Public Understanding of Science 10(1): 1-18. https://doi.org/10.3109/a036852.

—. 2014. "From Deficit to Democracy (Re-Visited)." Public Understanding of Science 23(1): 71-76. https://doi.org/10.1177/0963662513510646.

—, and Brian Wynne, eds. 1996. Misunderstanding Science? The Public Reconstruction of Science and Technology. Cambridge: Cambridge University Press. 
Jasanoff, Sheila. 2003a. "Technologies of Humility: Citizen Participation in Governing Science." Minerva 41: 223-244. https://doi.org/10.1023/A:1025557512320.

—.2003b. "Breaking the Waves in Science Studies: Comment on H. M. Collins and Robert Evans, 'The Third Wave of Science Studies'." Social Studies of Science 33(3): 389-400. http://www.jstor.org/stable/3183123.

Leurs, Koen. 2017. "Feminist Data Studies: Using Digital Methods for Ethical, Reflexive and Situated SocioCultural Research." Feminist Review 115: 130-154. https://doi.org/10.1057/s41305-017-0043-1.

Lezaun, Javier, and Linda Soneryd. 2007. "Consulting Citizens: Technologies of Elicitation and the Mobility of Publics." Public Understanding of Science 16(3): 279-97. https://doi.org/10.1177/0963662507079371.

Malanga, Sarah E., Jonathan D. Loe, Christopher T. Robertson, and Kenneth S. Ramos. 2018. "Who's Left Out of Big Data?: How Big Data Collection, Analysis, and Use Neglect Populations Most in Need of Medical and Public Health Research and Interventions." In Big Data, Health Law, and Bioethics, edited by I. Glenn Cohen, Holly Fernandez Lynch, Effy Vayena, and Urs Gasser. 98-111. Cambridge: Cambridge University Press.

Marsh, Sarah. 2021. "GPs Warn Over Plans to Share Patient Data with Third Parties in England." Guardian, May 30, 2021. https://www.theguardian.com/society/2021/may/30/gps-warn-plans-sharepatient-data-third-parties-england.

Martin, Sam, and Joyce Tait. 1992. "Attitudes of Selected Public Groups in the UK to Biotechnology." In Biotechnology in Public: A Review of Recent Research, edited by John Durant. 28-41. London: Science Museum.

Murgia, Madhumita. 2021. "England's NHS Plans to Share Patient Records with Third Parties." Financial Times, May 26, 2021. https://www.ft.com/content/9fee812f-6975-49ce-915c-aeb25d3dd748.

NHS Digital. 2021a. "Collection of GP Data for Planning and Research to Go Ahead on 1 September 2021." June $8,2021$.

https://digital.nhs.uk/news-and-events/latest-news/collection-of-gp-data-for-planning-andresearch-to-go-ahead-on-1-september-2021.

—. 2021b. "National Data Opt-out, June 2021." June 10, 2021. https://digital.nhs.uk/data-andinformation/publications/statistical/national-data-opt-out/june-2021.

—. 2021C. "National Data Opt-out, July 2021." July 22, 2021. https://digital.nhs.uk/data-andinformation/publications/statistical/national-data-opt-out/july-2021.

—. 2021d. "GP Data for Planning and Research: Letter From Parliamentary Under Secretary of State for Health and Social Care to General Practices in England." July 19, 2021. https://digital.nhs.uk/dataand-information/data-collections-and-data-sets/data-collections/general-practice-data-forplanning-and-research/secretary-of-state-letter-to-general-practice.

- 2021e. "National Data Opt-Out Open Data Dashboard." Last edited August 3, 2021. https://digital.nhs.uk/dashboards/national-data-opt-out-open-data.

—. 2021f. "Trusted Research Environment Service for England." Last edited August 27, 2021. https://digital.nhs.uk/coronavirus/coronavirus-data-services-updates/trusted-researchenvironment-service-for-england. 
Rochon, Paula A., Azad Mashari, Ariel Cohen, Anjali Misra, et al. 2004. "The Inclusion of Minority Groups in Clinical Trials: Problems of Under Representation and Under Reporting of Data." Accountability in Research 11(3-4): 215-223. https://doi.org/10.1080/08989620490891412.

Rowe, Gene, Tom Horlick-Jones, John Walls, and Nick Pidgeon. 2005. "Difficulties in Evaluating Public Engagement Initiatives: Reflections on an Evaluation of the UK GM Nation? Public Debate about Transgenic Crops." Public Understanding of Science 14(4): 331-52. https://doi.org/10.1177/0963662505056611.

Sciencewise. ‥d. About Sciencewise. Accessed September 7, 2021. https://sciencewise.org.uk/aboutsciencewisel.

Selin, Cynthia, Kelly Campbell Rawlings, Kathryn de Ridder-Vignone, Jathan Sadowski, et al. 2016. "Experiments in Engagement: Designing Public Engagement with Science and Technology for Capacity Building." Public Understanding of Science 26(6): 634-49. https://doi.org/10.1177/0963662515620970.

Smallman, Melanie. 2017. "Science to the Rescue or Contingent Progress? Comparing 10 Years of Public, Expert and Policy Discourses on New and Emerging Science and Technology in the United Kingdom." Public Understanding of Science 27(6): 655-73. https://doi.org/10.1177/0963662517706452.

Stirling, Andy. 2008. "'Opening Up' and 'Closing Down': Power, Participation, and Pluralism in the Social Appraisal of Technology." Science, Technology, \& Human Values 33(2): 262-94. https://doi.org/10.1177/0162243907311265.

TallBear, Kim. 2013. "Genomic Articulations of Indigeneity." Social Studies of Science 43(4): 509-533. https://doi.org/10.1177\%2F0306312713483893.

Taylor, Mark J., and James Wilson. 2019. "Reasonable Expectations of Privacy and Disclosure of Health Data." Medical Law Review 27(3): 2019, 432-460. https://doi.org/10.1093/medlaw/fwzoog.

Thorpe, Charles, and Jane Gregory. 2010. "Producing the Post-Fordist Public: The Political Economy of Public Engagement With Science." Science as Culture 19(3): 273-301. https://doi.org/10.1080/09505430903194504.

Walker, Peter. 2021. "Labour Asks NHS and Matt Hancock to Pause Plans for Sharing Patient Data." Guardian, June 6, 2021. https://www.theguardian.com/society/2021/jun/06/labour-asks-nhs-and-matthancock-to-pause-plans-for-sharing-patient-data.

Whitmarsh, Lorraine. 2011. "Scepticism and Uncertainty About Climate Change: Dimensions, Determinants and Change Over Time." Global Environmental Change 21(2): 690-700.

https://doi.org/10.1016/i.gloenvcha.2011.01.016.

Wynne, Brian. 1989. "Sheep Farming after Chernobyl: A Case Study in Communicating Scientific Information." Environment Science and Policy for Sustainable Development 31(2): 10-39. https://doi.org/10.1080/00139157.1989.9928930.

—. 2007. "Public Participation in Science and Technology: Performing and Obscuring a PoliticalConceptual Category Mistake." East Asian Science, Technology and Society: An International Journal 1(1): 99-110. https://doi.org/10.1007/s12280-007-9004-7.

Zuboff, Shoshana. 2019. The Age of Surveillance Capitalism: The Fight for a Human Future at the New Frontier of Power. London: Profile Books. 